\title{
KRONIK
}

\section{Çin Ekonomisinde Neler Oluyor?}

Yrd. Doç. Dr. Ferda Dönmez Atbaşı, A.Ü: Siyasal Bilgiler Fakültesi

Özellikle 2000'li yılların başından beri iktisadi büyüme denince akla gelen ilk ülke olan Çin, büyüme oranlarındaki göreli düşüş ve finansal piyasalarındaki dalgalanma ile bir anda bütün dikkatleri üzerinde topladı. Çin krize giriyor ve ticaret bağlantıları nedeniyle bütün dünyayı da peşinden sürüklüyor tartışmaları ana akım iktisat çevrelerinde çokça dillendirilmeye başlarken, IMF çevreleri de reformların artması ve hızlanması konusunda yüksek sesle konuşmaya çoktan başladı bile. Dünyanın merkezini, Çin'deki 'piyasaya eklemleyici' reformların hızlanması gerektiği hususunda bu kadar tedirgin eden gelişmeleri hatırlayalım:

- Temmuz 2015'ten itibaren Çin Borsalarındaki düşüş

- Ağustos 2015’te arda arda gelen yüksek oranlı iki devalüasyon

- \%10'lar civarında olan büyüme oranının \%7-6 civarına gerilemesi

\section{Borsadaki Düşüş}

En baştan belirtmek gerekir ki, herhangi bir ülke borsasındaki düşüşün, o ülkenin reel sektöründe yaratacağı çöküntünün etkisi borsanın derinliği ile doğru orantılıdır. Eğer borsa aracılığıyla fon yaratan firmalar, başka fon kaynakları kullanan firmalara oranla sayıca ve üretim kapasitesi olarak daha düşükse, borsada yaşanan bir çöküntünün etkileri sınırlı olur.

Sözkonusu Çin olduğunda borsadaki düşüşün ekonominin geneli üzerindeki etkisinin sınırlı olduğunu söylemek yanlış olmaz (Boratav, 2015). Hala birçok üretici firmanın ve bankaların devlet mülkiyetinde olduğu ve GSYH'ya oranla hisse senedi piyasası kapitalizasyonunun batı ekonomilerine oranla düşük olduğu bir ekonomide yaşanan borsa çöküntüsü, yapısal bir kırılganlığa işaretten çok bir uyarıcı niteliğindedir. Nitekim Çin ekonomisi 
üzerinde uzmanlaşan bir çok analist de, Çin otoritelerinin derhal refleks göstererek durdurduğu bu çöküşün çok da önemli olmadığı görüşünde birleşiyor (Gosh, 2015).

Borsa çöküşünün boyutlarını ve çöküşü durdurmaya yönelik tedbirleri hatırlamaya çalışalım. 7 Temmuz 2015 tarihi itibariyle Çin borsasında 1.4 trilyon ABD doları değerindeki hisse senedinin herhangi bir işlem yapması askıya alınmıştı (borsadaki şirketlerin dörtte birinin işlemlerinden söz ediyoruz). 12 Haziran 2015'ten Temmuz başına kadar Shangai endeksi \%26.9 değer kaybederken, Shenzen'de kayıplar \%35'e ulaştı. Bu gelişmeler karşısında Çin yönetiminin aldığı tedbirler otoritelerin paniğe kapılmalarının bir göstergesi olarak okunabilir. İlkin Merkez Bankası faiz oranlarını düşürdü ve bankaların genişleyici bir kredi politikası izlemesinin önünü açtı. Halka arz işlemleri iptal edilerek, 21 aracı firmanın oluşturduğu yaklaşık 20 milyar dolarlık bir fonun hisse senetlerini satın alması onaylandı. Aracı kuruluşlara likidite desteği yapılacağı ilan edilirken, Çin'in resmi rezerv dışındaki birikimlerini temsil eden 'bağımsız varlık fonu' (soverign wealth fund) aracılığıyla hisse senedi alımına başlandı (Akçay, 2015a). Başlangıçta yarattıkları sonuçlar itibariyle yetersizmiş gibi görünsede sözü edilen tedbirler çöküşü yavaşlatmayı ve geçici durdurmayı başard1.

Sı ̆̆ bir borsanın çöküşünün Çin reel ekonomisinde ve dolayısıyla dünya ekonomisinde büyük sorunlar yaratmayacağ 1 beklentisi biraz da, 4 trilyon dolarlık bir resmi rezerv hesabına sahip Çin merkez bankasının varlı̆̆ına dayanıyordu. On yıllardır devam eden cari fazlalar ve sonucunda ortaya çıan devasa döviz rezervinin, olası bir finansal çalkantıyla kolaylıkla başedebileceği algis1 yaygindi.

\section{Devalüasyonlar}

Çin Merkez Bankasına ard arda iki devalüasyon yaptıran dinamiklerinden üzerinde durmadan, bu politikaları anlamlandırmak pek mümkün görünmüyor. 2008'de Amerikan gayri menkul piyasalarında başlayan ve takip eden aylar içinde tüm dünyayı etkisi altına alan ekonomik buhranın dış ticaret hacimleri üzerinde yarattı̆ 1 tahribat şimdiye dek pek çok kez yazıldı. Çin'in baş ithalatçısı olan ABD ekonomisindeki olumsuzluk kendi ticaretini ve dünya ticaretini daraltırken en büyük darbeyi elbette Çin ihracatlarına vurdu.

Temel büyüme stratejisi ihracat artışları olan Çin ekonomisi için ihracat daralması devam ettiği sürece öngörülen büyüme oranının tutturulması giderek zora gireceğinden, merkez bankası bunu önlemeye yönelik tedbir almak zorundayd1. 
Diğer yandan, Amerikan Merkez Bankası FED'in bizim gibi eonomileri de çok ilgilendiren faiz kararı, tüm dünya ekonomilerinde olduğu gibi Çin'de de yakından takip edilmektedir. FED'in yakın zamanda uygulayacağını ilan ettiği faiz arttırımı politikası hayata geçerse, sermaye akımlarının yönünde bir değişikliğe yol açacağı aşikardır. Merkezden çevreye akan fonların, yükselen faiz haddinin çekiciliğine kapılarak ABD ekonomisine yönelmesi ihtimaline karşılık, Çin Merkez Bankası önceden bir önlem olarak devalüsyon yoluna gitmiştir (Akçay, 2015b).

\section{Büyüme Oranlarındaki Düşüş}

Çin milli geliri 1977 ile 2015 arasındaki 38 yıllık dönem boyunca her yıl, \% 6'nın üzerinde bir büyüme rakamını yakalamayı başarmıştır. Üstelik dünya ekonomisinin 1929 'dan sonra yaşadığı en büyük buhran olan 2008'i de içeren yakın dönemlere odaklandığımızda, 2000-2011 boyunca ortalama \%10'luk bir büyüme çizgisini sürdürdügünü görürüz (Boratav, 2015). Dünyanın geri kalannda çok düşük ya da negatif milli gelir büyüme oranları tecrübe edilirken, \% 6-7 büyümenin krize işaret olduğunu ileri sürmek fazla iddalı bir sav olur.

Peki bütün bu sıradışı büyüme performansı tarihi bir yanda dururken, Çin'in büyümesini yavaşlatan etmenler nelerdir? Çin ekonomisi yakın dönemde ne çeşit dönüşümlerden geçmektedir?

\section{Çin'de Ekonomisi Değişiyor}

Çin ekonomisi 2008 yılına değin birbirini takip eden iki on yıl boyunca, neredeyse o zamana kadar emsali görülmemiş bir büyüme performansını gerçekleştirirken, dünyanın merkezinde çıkan kriz, daha önce de belirttiğimiz gibi Çin için de büyük bir darbe olmuştur. İhracat hasılatındaki düşüşler, yerli talebin canlandırılmasına olan ihtiyacı arttırmıştır. Ancak, Çin otoriteleri ticari rekabetin en önemli unsurlarından biri olan düşük ücret politikasından vazgeçip harcamalar yoluyla geliri büyütmek yerine, birikimi daha da arttırarak büyüme yolunu tercih etmişlerdir (Ghosh, 2015). Zaten neredeyse milli gelirin yarısına eşit büyüklükteki yatırım harcamalarının 2008-09 döneminde hayata geçirilen kurtama paketi ile daha da arttırılması hedeflenmiştir. Böyle bir politikanın yarattığı ortam, özellikle kamu sektörü işletmelerinin yüksek oranlarda borçlanarak altyapı ve inşaat sektörlerinde yatırım yapmasına yolaçmıştır. Sonuç olarak önceki dönemlerde yaratılmış aşırı kapasite daha da artmıştır. Diğer yandan gayri menkul sektörünü canlı tutmak için faiz aktif bir politika olarak kullanılmış ve bu da yakın dönem büyümenin önemli bileşenlerinden biri olmuştur. 
Bahsi geçen yatırımların tamamına yakını Çin mali piyasalarının temel aktörleri olan kamu bankalarından alınan kredilerle finanse edilmekteydi. Fakat, gayri menkul piyasaları fiyatlarda aşırı şişkinlik oluştuğu sinyallerini vermeye başladıktan sonra, kamu bankalarının bu sektöre kredi vermesine sınır getirildi ve mevduat ve kredi faiz oranları da yeniden gözden geçirildi (Ghosh, 2015). Bu kısitlamalar 'gölge bankacılık' denen yeni bir formun oluşmasının zeminini hazırladı. Banka-dışı çeşitli mali kuruluşlar, 'servet idaresi' ürünleri diyebileceğimiz yüksek getirili enstrümanları piyasaya sunarak gayri menkul ve inşaat sektörlerindeki şişkinliğin devamını sağladılar. Mali otoritelerin bu sürece müdahale edecek herhangi bir politika önlemi almamış olması açılanmayı bekleyen bir husus olarak görünmektedir (Ghosh, 2015).

İhracattaki daralmayı dengeleyecek hamle olarak yatırımların daha da arttırılması ve kamu bankaları ve gölge bankalar eliyle gayri menkul sektörünün bir balona dönüşmesi, Çin ekonomisinin borçluluk örüntüsünün dramatik bir şekilde değişmesiyle sonuçlandı. Çin ekonomisindeki toplam borç, 2007-14 döneminde cari yerel para birimi cinsinden dört misli artarak, borçluluk/GSYH oranını iki katına çıkardı (bu rakam örneğin ABD borçluluk/GSYH oranından daha yüksektir). Şirketler sektörünün borçluluk oranı milli gelirin \% 125'ini bulurken, hane halklarının borçluluk oranları da mili gelirin \% 65'ine ulaştı. Nihayetinde Çin'in büyük şehirlerindeki gayri menkul piyasalarında oluşan fiyat balonları patladı. Böyle kriz anlarında eldeki varlığın değeri düştüğü için bir ödeme güçlüğü zinciri oluştuğunu önceki kriz deneyimlerimizden biliyoruz. Çin örneğinde de böyle oldu. Mayıs 2015'e gelindiğinde Çin'in 70 kentindeki ortalama ev fiyatları \% 10 düşmüştü (Ghosh, 2015).

Borsa krizi böyle bir arka planın varlığında ortaya çıktı çünkü gayri menkul piyasasındaki balonun patlamasıyla yatırımcıların dikkati hisse senedi piyasalarına çevrildi. Borsa krizinin patlak vermesinden önceki bir yıl içinde, borsa endeksleri bir buçuk kat artarak anomalinin şaretlerini vermeye başlamıştı. Elbette borsa yatırımcıları da bu sinyalleri doğru okuyup satışa geçtiler ve 2015 'in temmuzunda hisseler tepe noktasının \% 50 daha altında bir fiyattan işlem görmeye başladı (Ghosh, 2015).

Yazının henüz başında borsanın çökmesi üzerine Çinli otoritelerin aldığ tedbirlerden zaten bahsetmiştik. On yıllardır, kendinden emin bir atmosferde büyüyüp genişleyen ve krizlerle karşılaşmaksızın güç kazanan bir yarı-piyasa ekonomisinin yaşadığı bu ilk büyük şokla epey sarsıldığını söylemek yanlış olmaz. Borsada hisse senedi satışlarını askıya almak, aracı kurumları ellerindeki hisse stoklarını satmaktan men etmek gibi piyasa-dışı ve panik göstergesi tedbirler Çin hükümetinin kendine olan güvenini sarstığı kadar, ticaret bağlarıyla Çin'e ve birbirlerine bağlı tüm dünya ekonomilerinin de gözünü korkutmuştur. Sözkonusu tedbirler başlangıçta çalkantıyı durdurmakta 
zorlanmış gözükse de, nihayetinde Çin piyasaları bu yazının yazıldığı sırada durulmuş gözümektedir.

Öyleyse, Çin ekonomisi krizde midir? Bir çırpıda cevaplamak zor, ancak görünen odur ki, gayri menkul piyasalarındaki şişkinliğin patlaması ve ardından borsadaki çalkantı, 2008 krizinden kaynaklı ihracat düşüşlerinin ve dolayısıyla milli gelir büyümesinde bir yavaşlamanın yaşandığı döneme denk gelmiştir. Böyle bir çalkantı döneminden daha çok yatırım yaparak çıkma beklentisinin ne kadar gerçekçi olduğunu hep birlikte göreceğiz ancak yaşanan sıkıntıların sadece Çin'de değil, bütün ticaret ve finans partnerlerinde hissedileceği açıktır.

Gözlemlerimizden çıkan bir başka sonuç, Çin gibi reel çevrim ve finans çevriminin önemli ölçüde devlet kontrolünde olduğu bir ekonominin kademeli de olsa finansal serbestleşmeye geçmesinin hayırdan çok şer getirdiğidir. Bretton Woods kuruluşlarının dillerine pelesenk ettiği daha çok reform, daha fazla serbestleşme talepleri, az gelişmiş, gelişmekte olan ya da büyüme rekortmeni hiçbir ekonomiye doğrudan bir yarar sağlamadığı gibi, dünyanın bir yerinde gerçekleşen bir krizi sağlıklı ekonomilere de bulaştırmanın mekanizmalarını yaratarak yıkım getirmiştir.

Büyüme şampiyonu, geleceğin hegemonu, ya da dünya kapitalizminin ejderhası Çin'in, bu ünvanlara nasıl eriştiği sınıfsal açıdan ele alınacak olursa, emekçi kesimlerin düşük ücret ve kötü çalışma koşullarına tabi olarak yarattığ ücret rekabetinin payının büyüklüğü karşımıza çıkan ilk araştırma nesnesi olarak orta yerde durmaktadır.

Grafik 1'de örnek olarak 2001-2010 döneminde kayıt dış1 istihdamın bileşimi ve toplam istihdama göre büyüklüğü izlenebilir. 2001'de kayıt diş1 istihdamın payı \%30,2 iken 2010'a gelindiğinde bu oran sadece 0,5 puan azalmıştır. 2001'de kayıt dış1 istihdam edilenlerin \%87,3'ü göçmen işçilerden oluşurken 2010'da bu oran \% 60,7'ye gerilemiştir, fakat kayıt dışı çalışma ciddi bir örüntü olarak görülmeye devam etmektedir. Keza kentli işçilerin kayıt dışı istihdamdaki payları da neredeyse iki kat artmıştır (Değirmenci, 2013). 
Grafik 1: Kentsel Emek Piyasasında Kayıt Dışı İstihdamın Bileşimi ve Büyüklüğü F

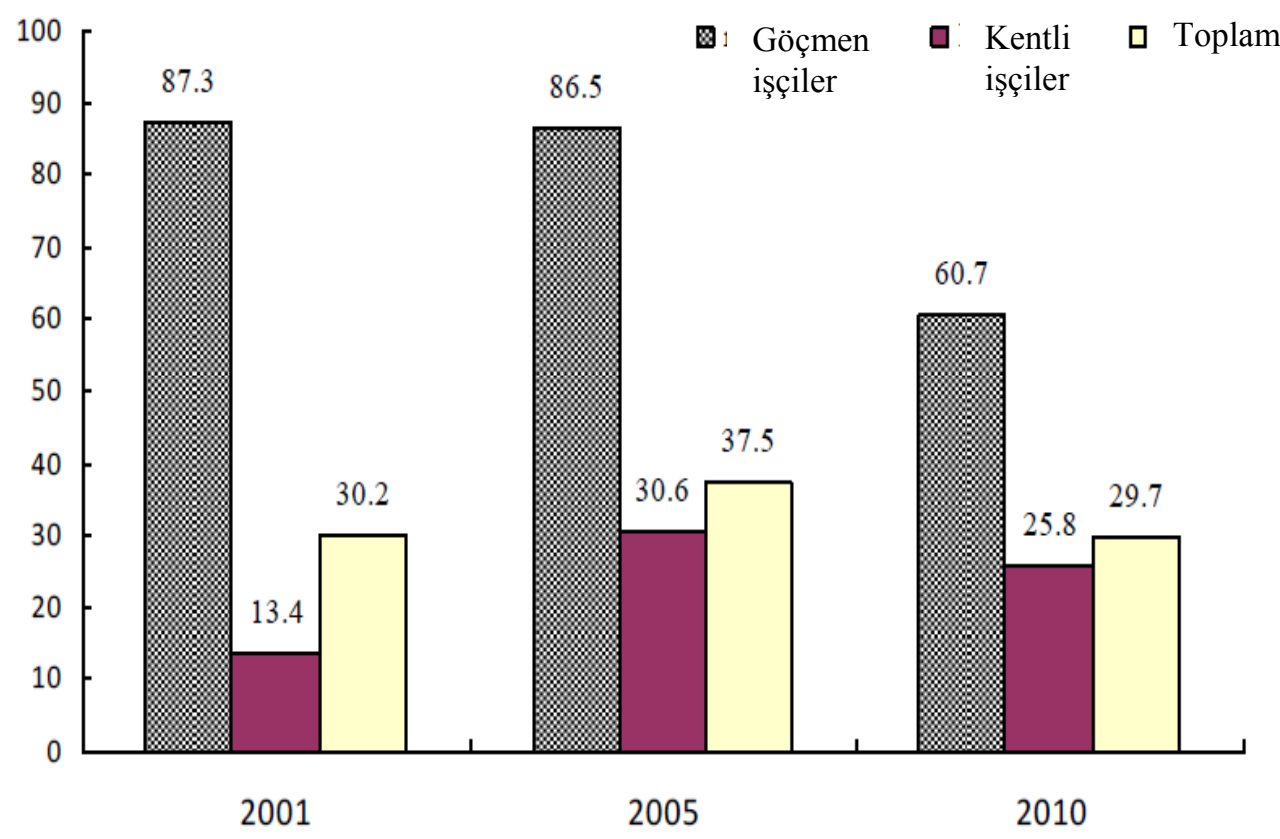

Kaynak: Değirmenci, 2013.

Çok açıktır ki, Çin'in ekonomik büyümesi, iktisadi ve sosyal eşitsizliklerin pekişmesiyle gerçekleşmektedir. Çok basit bir örnek vermek gerekirse, 1990-2005 döneminde Çin emek gelirlerinin GSYİH'ya oranı \%50'den \%37'ye gerilemiştir (Değirmenci, 2013).

Faktörel gelir dağılımı ve sınıfsal mücadelere ilişkin geniş kapsamlı bir analize duyulan ihtiyacı saklı tutarak belirtmek gerekir ki, kapasiteye yapılan yatırımlara rağmen gerçekleşen milli gelir yavaşlaması mevcut emek rejiminin sürgit devam edemeyeceğinin göstergesidir. Şu halde, Çin sermayesi ve emekçi sınıfi arasındaki mücadelenin kimden yana bir rotaya gireceği, özellikle finans piyasalarında ne çeşit reformların hayata geçireleceği Çin ekonomisinde neler olacağının belirleyicileri olacaktır. Etkilerini hep birlikte gözleyeceğiz. 


\section{Kaynaklar}

Akçay, Ümit (2015a), http://kriznotlari.blogspot.com.tr/2015/08/cin-kuresel-ekonomiyisarsyor.html

Akçay, Ümit (2015b), http://kriznotlari.blogspot.com.tr/2015/07/cinde-borsa-cokusu-veintimaller.html

Boratav, Korkut (2015), http://sendika1.org/2015/09/cin-krizde-mi-korkut-boratav/

Değirmenci, Ekin (2013), “Çin: Büyümenin Sürdürülebilirliği”, yayınlanmamış seminer makalesi.

Ghosh, Jayati (2015), http://www.frontline.in/columns/Jayati_Ghosh/taking-stock-inchina/article7447539.ece 